\title{
Instituto Nacional de Seguridad y Salud en el Trabajo: Enciclopedia Práctica de Medicina del Trabajo
}

\author{
M. T. Vicente-Herrero \\ Madrid: Servicio de Ediciones y Publicaciones INSST; Diciembre 2018. NIPO276-18-073-6 \\ DOI: $10.12961 /$ aprl.2019.22.03.4
}

El 23 de abril de 2019 se presentó en Madrid, en la sede del Instituto Nacional de Seguridad y Salud en el Trabajo (INSST), la Enciclopedia Práctica de Medicina del trabajo, texto largamente esperado, cuya redacción ha supuesto más de tres años de trabajo para 63 autores de distintas especialidades sanitarias, que está disponible con acceso libre y en formato digital en la página web del INSST.

Se trata de un texto recopilatorio de 4.150 páginas, que incluye 760 tablas y 370 imágenes o figuras, distribuido en tres volúmenes que contienen a su vez 26 cuadernos individualizados por especialidades y materias específicas.

Supone un abordaje novedoso en los aspectos docentes y de consulta para los especialistas en salud laboral en ejercicio o en periodo de formación y pretende asimismo aportar información sobre la medicina en el mundo del trabajo y prevención de riesgos a especialistas de otras disciplinas sanitarias que deseen consultar algún aspecto concreto que afecte a las personas que trabajan, especialmente en relación con posibles limitaciones o patologías relacionadas con la exposición a riesgos laborales.

En sus diferentes volúmenes y cuadernos se incluyen contenidos relativos a todas las competencias del médico y enfermero del trabajo dentro de la unidad básica de salud laboral: desde los riesgos del puesto y su evaluación, la valoración del daño, la formación e información necesarias, la atención de urgencias y emergencias, la vigilancia especifica de la salud, la promoción de la salud en su sentido más amplio y la investigación; todo ello para cada una de las especialidades y con apoyo de aspectos complementarios como las nuevas técnicas de comunicación, o la valoración de las técnicas radiológicas y pruebas de imagen y sus aportaciones en el ejercicio diario.

La formación es, sin duda, la pieza clave para que, a través del conocimiento, se pueda desarrollar una disciplina o especialidad. Lograr el progreso y mejora de la medicina tiene sus dos pilares básicos en la docencia, como punto de partida, y en la investigación como motor de avance. Sirva esta enciclopedia para ayudar a quienes ejercen, formar a quienes están en su periodo de residencia, difundir la especialidad entre todos los sanitarios y prevencionistas y apoyar a la salud laboral mediante la divulgación que se pueda lograr con un texto de estas características.

Su uso y utilización mostrará si los objetivos planteados inicialmente en su redacción se han logrado y abrirá el camino a posteriores mejoras y revisiones de sus contenidos.
Se une así a otros libros ya publicados para aportar una visión global de la medicina del trabajo como materia troncal relacionada con todas las demás especialidades médicas y preventivas en un marco de trabajo conjunto, pero con el abordaje específico desde la perspectiva laboral que nos identifica como especialistas.

Sirva esta enciclopedia, como dice Javier Pinilla, director del INSHHT, esta enciclopedia puede ser utilizada como material de docencia y divulgación de la Medicina del Trabajo, como especialidad médico-preventiva, dirigida a todas las disciplinas en torno a la Salud Laboral, en un marco preventivo y de mejora de la calidad de vida de las personas que trabajan.

\author{
$M^{a}$ Teófila Vicente-Herrero \\ (dirección y coordinación del texto) \\ Responsable Medicina del Trabajo \\ SPP Grupo Correos de Valencia y Castellón \\ vicenteherreromt@gmail.com
}

